\title{
Second Language Spoken Learning Research Based on Oral Memory Capacity Constraints
}

\author{
Ya Wang \\ Shandong College of Tourism and Hospitality, Ji'nan Shandong 50200
}

Key Words: Memory capacity, Second language learning, Spoken language teaching.

\begin{abstract}
Working memory capacity is an important factor to impact second language learners' spoken learning, this paper studied this factor, selected 110 non-English majors, measure these students' working memory capacity, use spoken language breadth measurement method to assess three main aspects, namely, oral fluency, pronunciation, diction accuracy and complexity. Analysis showed that the degree of second language fluency, accuracy and working memory capacity is related to each other, but not associated with the complexity of spoken language, it is easily seen that working memory capacity is an important factors to restrict spoken language teaching effect.
\end{abstract}

\section{Introduction}

Working memory capacity, as a limited memory system is capable of information processing, storage, so that the information has a temporary storage function, to help learners to understand, study and inference knowledge, help people’s cognition. Working Memory Capacity researchers believe that human cognitive behavior of individuals in the information processing or storage are constrained by memory capacity; memory capacity is different, there are differences on the cognitive activity; cognitive activity if working memory capacity beyond the prescribed limits will remember the ability to process information and store information weakens, thus, working memory capacity is different, or stored on the information processing speed and accuracy also showed differences. This article will analyze the effect that memory capacity limitation on the spoken teaching for second language learners.

\section{Effect Factor Analysis of Working Memory Capacity Limit on Spoken Language Output}

Spoken language output is a complex and lengthy process of awareness, spoken language output is often constrained by memory capacity affect learning spoken language, in which cognitive activities can be organized, intentional concept of words, meaning intentions, syntax and speech, etc. encoding process, but also on the vocal organs vocal control, monitor and make adjustments to the speech, closely co-ordinated work together to complete a full set of speech production process, but also in an alternating manner above output, it would be the second language learning who bear a greater load of memory and learning tasks. If working memory is higher than the normal working memory capacity, there will be oral presentation is slow, pause and repeat, make oral fluency affected, and working memory capacity to distinguish between different individuals, some individuals fluent expression, accurate expression, but some individuals will difficult to achieve. With the deepening of working memory capacity study, the research shows that working memory capacity of the output has spoken to certain restrictions. The above studies show that working memory capacity have a lot of influence in other areas, but the time is short study, and research is limited, can not get accurate answers in fluency, accuracy and complexity, the need for further study of these relationships . Furthermore, in the current study, the breadth of the oral test and measurement process in working memory capacity, 
are not fully taken into account and the analysis of this factor. Some scholars have found that reading span, if not limited, you can use a number of strategies for word memory, these measures enhance memory not only did not improve memory efficiency, but also makes reading achievement and test scores reduced in a 2003 experiment, to make reading the breadth and depth affected. Currently, many scholars have spoken during the span test, the test is still using the association method and repeat method, the word is not too much processing time, thus, can be spoken in breadth on the efficiency and validity of the test to be considered to ensure that you can test depth achieve. Also, in the breadth of oral tests, second language learners to memorize words even strong, but we can not guarantee that the sentence meaning and grammar is correct. Thus, the need for second language learners Speaking Span Test in processing capacity and storage capacity to fully reflect, taking into account the processing accuracy and processing efficiency.

\section{Second language learners spoken language teaching research under capacity limit}

\section{The subject}

Select 110 non-English major freshmen as an object of study, in which 63 boys and 47 girls. The average age is around 20 years old.

\section{Test method and data colection}

Subjects who carry out the above three tests, the main contents include: Oral breadth of working memory capacity is measured; for fluency, accuracy and complexity measure; Second Language level English test. Breadth first spoken language test, carried out this experiment to test the breadth of Oral and working memory tests, specific test method reference Forkamp Speaking Span Test Method 2003 research, applied testing among 50 English words, and are high frequency vocabulary, these units will be divided into two groups, each group with 1 or 3 words, to prevent the emergence of similar tests all use associative memory, each word in a phrase cannot be associated with the meaning or pronunciation in or on the place. Speaking Span Test all use an integrated and comprehensive easing strict spoken breadth breadth spoken, namely, CSSS, CLSS two different scoring points. 1996 combined reading span test design rationale, referring to the breadth of test calculations for two scores and working memory ${ }^{[2]}$.

Spoken language output test. Spoken language output test using the test method described image output Spoken induction. Image description method is a very common method, capable of dialogue than output, more interviews have effect, can be more effective on the spoken second language learners a comprehensive reflection. Study on Oral complexity, accuracy and fluency explained as follows:

Complexity (C / T): the number of each clause in a $\mathrm{T}$ unit has also divided the subject omitted word sentences and phrases, phrases. Accuracy (ACC): Accuracy is to find out the number of errors from a number of semantic units. Including complete and incomplete word semantics, incomplete word but also a vowel and a consonant. Including syntax, vocabulary selection and lexical errors, but does not contain errors on voice. Speed (SR): the number of syllables and words represent a sample of speech generated time, the ratio of the total number of the result by 50 to obtain the number of syllables per minute. Second Language Proficiency Test papers including listening, speed reading, writing, reading comprehension and translation ${ }^{[3]}$.

\section{Study steps}

First the students' proficiency level test in a classroom complete all tests. Then on the computer Speaking Span Test, subjects who one person, one computer, teaching and research staff to be emphasized that the subject of the word prototype, and subjects were asked to follow the order of words and sentences, sentence length and cost because the content is different, and that is the length of the the content and form of limitation, it must semantics and syntax is correct. Carry out a test before the first official practice, the subject to be able to gradually adapt the test to ensure that play a normal level. Speaking in a voice test lab, got the pictures to students to stay after 10 minutes preparation time, upon completion of the test after the end of the story narrative, the expression time is usually within 10 minutes, the spoken subject recording into MP3 format files . 


\section{Systemize and analyze for data}

For breadth collected oral test MP3 files, the researchers can be converted to text format, for each subject spoken breadth and loose breadth score is calculated, that is, SSS and LSS results, but also on the processing accuracy calculation and storage capacity results. Then use Audition 1.5 software for the correct pronunciation of each subject and presentation of summary record time, calculate the average response time, the above results summary as a comprehensive oral test scores. Speaking for MP3 files, you can convert it to text format, and then pause to check in time whether or not filled pause time determined filled with unfilled pauses, these pauses promptly recorded for every pause interval the number of syllables statistics, but also the subject of voice, rate of speech, phonation time, the average rate of speech fluency, pronunciation, speed, average dwell time is calculated, and then you can sample all semantic errors, T- number of units, clauses number tallied, accuracy and complexity of the calculation ${ }^{[4]}$.

\section{The result and discussion}

Second Language level All subjects were tested to obtain an average score of 70.54, standard deviation obtained was 7.5, the highest score of 90 points, the lowest score 40 points. Test reliability coefficient of 0.85 , which illustrate the most credible way of second language test papers. 50 words spoken breadth used in the test was divided into two groups according to the two groups of test results can be oral test internal reliability coefficient calculated breadth comprehensive strict spoken derived internal reliability coefficient of .70; Integrated oral loose breadth reliability coefficient was .70, higher than 0.8 , indicating that this method is a test of the credibility of a strong memory capacity test. Speaking of working memory test described in a statistics table below:

Table 1. Spoken language breadth descriptive statistics

\begin{tabular}{ccccc}
\hline & Peak value & Lowest value & Mean value & Standard deviation \\
\hline Strict speaking scope(SSS) & 37.00 & 8.00 & 24.19 & 5.43 \\
\hline Loosen speaking scope(LSS) & 43.00 & 8.00 & 25.98 & 5.57 \\
\hline Stime(ms) & 27331 & 4860 & 10824 & 4050 \\
\hline Ltime(ms) & 27331 & 4978 & 10818 & 4048 \\
\hline Storage & 45.50 & 18.00 & 30.95 & 4.63 \\
\hline CSSS & 1.61 & -1.78 & 0 & 0.68 \\
\hline CLSS & 1.78 & -1.79 & 0 & 0.68 \\
\hline
\end{tabular}

In this paper, the three indicators for the use of fluency, accuracy and complexity of spoken language output will be measured. Table 2 shows the results of statistical result for the indicators.

Table 2. Second language spoken language output descriptive statistics

\begin{tabular}{cccccc}
\hline & & Peak value & Lowest value & Mean value & Standard deviation \\
\hline & Speed & 163.10 & 76.06 & 112.21 & 16.51 \\
\hline Phonation ratio & 0.80 & 0.37 & 0.62 & 0.08 \\
\hline & Mean flow & 9.28 & 2.97 & 4.80 & 0.90 \\
\hline & Pronunciation speed & 3.94 & 2.23 & 3.02 & 0.37 \\
\hline Accuracy & Dwell time & 2.20 & 0.55 & 0.98 & 0.22 \\
\hline Complexity & & 27.22 & 4.79 & 15.18 & 4.56 \\
\hline
\end{tabular}

To make the working memory capacity to have more impact on the second language fluency, accuracy, complexity output; firstly consider the relations between the Working Memory Capacity and these indicators; by Table 3, the working memory capacity, fluency indicators SR, PTR, MLR, ALP and other indicators will be given. On the correlation between AR .0.1 is more significant, ACC beyond .oo1 will have correlation, but with the $\mathrm{C} / \mathrm{T}$ index correlation is not obvious.

Table 3. Working memory capacity and second language output indicator statistical table

\begin{tabular}{|c|c|c|c|c|c|c|c|c|}
\hline & & SR & PTR & MLR & AR & ALP & ACC & $\mathrm{C} / \mathrm{T}$ \\
\hline \multirow{2}{*}{$\begin{array}{c}\text { Pearson's correlation } \\
\text { coefficient r }\end{array}$} & CSSS & $.718 * * *$ & $.565 * * *$ & $.679 * * *$ & $.310 * * *$ & $.453 * * *$ & $.380 * * *$ & .085 \\
\hline & CLSS & $.733 * * *$ & $.561 * * *$ & $.694 * * *$ & $.330 * * *$ & $.452 * * *$ & $.404^{* * *}$ & .038 \\
\hline \multirow{2}{*}{$\begin{array}{c}\text { Coefficient of partial correla } \\
\text { tion } \mathrm{r}\end{array}$} & CSSS & $.569 * * *$ & $.508 * * *$ & $.544 * * *$ & .085 & .395 & .190 & .127 \\
\hline & CLSS & $.581 * * *$ & $.505 * * *$ & $.559 * * *$ & .098 & .396 & .213 & .017 \\
\hline
\end{tabular}


From the above table is found, working memory capacity and proficiency level there is a correlation, and correlation coefficient above $0.6(\mathrm{p}<.001)$. It can also be seen that the level of control variables in second language after working memory capacity and fluency indicators SR, PTR, MLR, ALP, the correlation is more significant.

\section{Specific Countermeasures on Spoken language teaching}

Based on the above studies have shown that memory capacity is an important factor limiting the impact of second language learning, second language teaching practice in order to make better results, you can use the following teaching methods.

\section{Teaching Strategies for Communicative Listening Ability}

Targeted communicative listening ability teaching strategies, teaching materials in the first recording session, the purpose of recording is to restore the true character of the text, let students to recite textbook in class, but rather a voice input, by listening to audio content expressed in textbooks, in this way not only fun but also to increase the teaching has a very strong vitality, the ability to focus on the students together, the most important thing is communication through listening training students listening ability and daily conversation skills. After completion of recording, the teacher can pick out a suitable question for students to answer. Secondly, quoted trained teachers based learning include textbooks or everyday common content, using the third person quoted, this method is well suited for text review.

\section{Teaching Strategies for Memory Abilities in Communication}

In spoken language class, allow students to learn what the occasion to say anything, so that second language learning really into a particular context, where "word" is the transfer of information as well as the structure of the scene, which are the focus of teaching content. In spoken language teaching should take the main scene, will point out the structure, thus helping students deepen their knowledge of the memory, can be applied flexibly spoken in real life, true to say speaking. If the text appears like "You're so scared" This situation, it said two meanings, one is similar to: home from school saw a dog running to its own, after the mother saw him outside the puppy and then I touched my head and said: "See you scared!" This is a more concerned tone to use; there is a, and several classmates to see who start and Taoism, halfway appears a dog, scared I suddenly stopped, then, several other students said: "See you scared!" this is a kind of ironic laugh or spoken language. A scene change in a real different colloquial tone, to enable students to deepen the understanding of the spoken language and learning, then, also named teacher of language structure, usage and the like. For example, you can be "looked at" transposition "looked" like. In short, the use of scenarios to strengthen the law L2 oral practice is more effective than complicated formulas or fragmented memories ${ }^{[5]}$.

\section{Teaching Strategies for Spoken Language Comprehensive Ability}

First, repeat. That is, listening to or reading the text after text general content expressed it, the other is a teacher said some students repeat a joke or fable, and added their views and ideas; speech, speech is an important means to express their own opinions, can be scheduled before the start of the course, allowing students to use their own data, vocabulary, sentence composition of some speech content, to speak in the classroom, you can not prepare any information, teachers are given a few key words so that students impromptu speech, more training students' thinking ability and oral presentation skills; discussions. All students will be divided into several groups of teachers mention the arguments for discussion, each to express their views and feelings, can make understanding and skills to be trained.

\section{Conclusion}

This article analyze memory capacity limit's effect on second language learners' spoken language learning, the performance of the memory capacity restrictions have a significant impact on verbal learning second language learners, second language teaching proposed several measures, is a comprehensive oral skills We need to develop learning strategies from various aspects, improve teaching effectiveness. 


\section{References}

[1] Liu Lihuang, Yu Xiaoping. For Second Language Learners Poor Spoken Language Communication Skills Pragmatic Research - Feasibility Blended Learning Model in College English Teaching in China, Science and Technology Information (Academic Edition), 2011 (34): 129-130.

[2] Sun Jie. Second Language Development Stage Study Based on Corpus Base, Foreign Languages Research, 2014 (3): 26-30.

[3] Ding Yanren, Qi Yan. Correlation Study between Word Block, English Speaking and Writing Level, Chunk use of PLA University of Foreign Languages, 2010,28 (3): 49-53.

[4] Miao Haiyan, Sun Lan. Syntax Structure Application and the Second Language Spoken Fluency Development Research, Language Teaching and Research, 2011,38 (5): 265-271.

[5] Chen Xinren. Baldness Countable Noun Phrase of Chinese Student Second Language Output the concept of cognitive and linguistic representation, Foreign Languages Research, 2010 (1): 15-20. 